\title{
Authority without privilege: How to be a Dretskean conciliatory skeptic on self- knowledge
}

\author{
Michael Roche* and William Roche† \\ * Department of Philosophy, Mississippi State University, MS, USA, \\ mjr454@msstate.edu \\ † Department of Philosophy, Texas Christian University, TX, USA, w.roche@tcu.edu
}

ABSTRACT: Dretske is a "conciliatory skeptic" on self-knowledge. Take some subject S such that (i) S thinks that P and (ii) S knows that she has thoughts. Dretske's theory can be put as follows: $\mathrm{S}$ has a privileged way of knowing what she thinks, but she has no privileged way of knowing that she thinks it. There is much to be said on behalf of conciliatory skepticism ("CS" for short) and Dretske's defense of it. We aim to show, however, that Dretske's defense fails, in that (in part) if his defense of CS's skeptical half succeeds, then his defense of CS's conciliatory half fails. We then suggest a potential way forward. We suggest in particular that the correct way of being a Dretskean conciliatory skeptic is to deny that $\mathrm{S}$ has a privileged way of knowing about her thoughts, but to grant that she is nonetheless an authority on her thoughts.

KEYWORDS: authority; conciliatory skepticism; contrastivist epistemologies; Dretske; McKinsey's paradox; privilege; self-knowledge; thought

\section{Introduction}

Dretske (2003a, 2003c, 2006b, 2011, 2012a, 2012b, 2012c) is a "conciliatory skeptic" on self-knowledge. ${ }^{1}$ Take some subject $\mathrm{S}$ such that (i) $\mathrm{S}$ thinks that $\mathrm{P}$ and (ii) $\mathrm{S}$ knows that she has thoughts. Dretske's theory can be put as follows:

Conciliatory Skepticism (CS): S has a privileged way of knowing what she thinks, but she has no privileged way of knowing that she thinks it.

This should be understood as restricted to occurrent conscious thoughts, where thoughts are non-factive propositional attitudes (hence $\mathrm{S}$ can think that $\mathrm{P}$ even if in fact $\mathrm{P}$ is false)

\footnotetext{
${ }^{1}$ Our focus here is on Dretske's later writings on self-knowledge. For discussion of his earlier writings (Dretske 1994, 1995, Ch. 2, 1999), see, e.g., Aydede (2003), Kemmerling (1999), and Lycan (1999).
} 
and essentially involve acceptance (hence $\mathrm{S}$ thinks that $\mathrm{P}$ only if she accepts that $\mathrm{P}$ ). ${ }^{2}$ Further, CS should be understood so that $\mathrm{S}$ has a privileged way of knowing a given fact only if she has a way of knowing it that is both (a) unavailable to others and (b) epistemically superior to others' ways of knowing it. $^{3}$

CS is a middle position: it is conciliatory on whether $\mathrm{S}$ has a privileged way of knowing what she thinks, but it is skeptical on whether $\mathrm{S}$ has a privileged way of knowing that she thinks it. It stands in contrast to a fully conciliatory theory according to which $\mathrm{S}$ has a privileged way of knowing both what she thinks and that she thinks it. It also stands in contrast to a fully skeptical theory according to which $\mathrm{S}$ has no privileged way of knowing either what she thinks or that she thinks it.

Crucial to understanding CS is to bear in mind that Dretske is a contrastivist on knowledge. He holds that knowledge is a ternary (as opposed to binary) relation $\mathrm{K}(\mathrm{S}, \mathrm{P}$, A) between a subject $S$, a proposition $P$, and a set of relevant alternatives A such that (i) $P$ is a member of A and (ii) exactly one member of A is true. ${ }^{4} \mathrm{CS}$ 's conciliatory side should thus be understood as:

${ }^{2}$ Dretske believes that his defense of CS can be generalized to mental states and events other than occurrent conscious thoughts (so understood), e.g., perceptual experiences (see Dretske 2003 b for relevant discussion). He restricts CS to occurrent conscious thoughts because his "plate is already too full" (Dretske 2012b, p. 2, n. 1). For discussion of other theories of self-knowledge, and for references, see Gertler (2017).

${ }^{3}$ How exactly (a) and (b) are to be unpacked is not entirely clear. But Dretske certainly holds that a given way of knowing can be privileged even if it is not infallible (see Dretske 2012a, p. 52). See Byrne (2018, Ch. 1) on "privileged access" and "peculiar access" for relevant discussion. See also Fernández (2013, Ch. 1) on "special access" and "strong access".

${ }^{4}$ This is perhaps most explicit in Dretske (1981b). But see also Dretske (1970, 1971, 1981a, 2005a, 2005b, 2006a). Sawyer (2015) has a different reading. She reads Dretske's theory of knowledge as a non-contrastivist theory on which knowledge is a binary relation — between a subject and a proposition — holding against a set of alternatives. This is okay for our purposes, however, since our main points about CS and Dretske's defense thereof would hold even if Sawyer's reading were assumed. For further discussion of contrastivist epistemologies, see, e.g., Blauuw (2008), Johnsen (2001), Rieber (1998), Schaffer (2005), and Sinnott-Armstrong (2004). 
$\mathrm{CS}_{\mathrm{CO}}$ : $\mathrm{S}$ has a privileged way of coming to stand in the knowledge relation $\mathrm{K}(\mathrm{S}, \mathrm{S}$ thinks that $\mathrm{P},\{\mathrm{S}$ thinks that $\mathrm{P}, \mathrm{S}$ thinks that $\mathrm{Q}, \mathrm{S}$ thinks that $\mathrm{R}, \ldots\}$ ).

CS's skeptical side, in turn, should thus be understood as:

$\mathrm{CS}_{\mathrm{SK}}$ : $\mathrm{S}$ has no privileged way of coming to stand in the knowledge relation $\mathrm{K}(\mathrm{S}, \mathrm{S}$ thinks that $\mathrm{P},\{\mathrm{S}$ thinks that $\mathrm{P}, \mathrm{S}$ hopes that $\mathrm{P}, \mathrm{S}$ fears that $\mathrm{P}, \ldots\}$ ).

The knowledge relations at issue in $\mathrm{CS}_{\mathrm{CO}}$ and $\mathrm{CS}_{\mathrm{SK}}$ are alike in their first and second terms. But they differ in their third terms.

It will help in terms of presentation to reformulate $\mathrm{CS}_{\mathrm{CO}}$ and $\mathrm{CS}_{\mathrm{SK}}$ in terms of contrastive focus (indicated by underlining):

$\mathrm{CS}_{\mathrm{CO}}$ : $\mathrm{S}$ has a privileged way of knowing that she thinks that $\mathrm{P}$.

$\mathrm{CS}_{\mathrm{SK}}$ : S has no privileged way of knowing that she thinks that $\mathrm{P}$.

The contrastive focus in $\mathrm{CS}_{\mathrm{CO}}$ serves to indicate that the relevant alternatives at issue differ in terms of the content of S's thought. The contrastive focus in $\mathrm{CS}_{\mathrm{SK}}$ serves to indicate that the relevant alternatives at issue differ in terms of the attitude that $\mathrm{S}$ bears towards P.

Dretske's theory is easily misunderstood. $\mathrm{CS}_{\mathrm{CO}}$ claims that $\mathrm{S}$ has a privileged way of knowing a certain proposition. Which proposition? The non-contrastive proposition: $\mathrm{S}$ thinks that $\mathrm{P} . \mathrm{CS}_{\mathrm{SK}}$ denies that $\mathrm{S}$ has a privileged way of knowing a certain proposition. Which proposition? The very same one: $\mathrm{S}$ thinks that $\mathrm{P}$. They don't differ, then, in terms of the proposition that $\mathrm{S}$ is said to have or not have a privileged way of knowing. They differ, rather, in terms of their sets of relevant alternatives. ${ }^{5}$

Because the knowledge relations at issue in $\mathrm{CS}_{\mathrm{CO}}$ and $\mathrm{CS}_{\mathrm{SK}}$ involve the same proposition (S thinks that $\mathrm{P}$ ), CS might appear to violate the following closure principle:

Closure: If (i) $\mathrm{S}$ knows that $\mathrm{P}$, (ii) $\mathrm{S}$ knows that $\mathrm{P}$ entails $\mathrm{Q}$, and (iii) $\mathrm{S}$ comes to believe that $\mathrm{Q}$ on the basis of this knowledge, then $\mathrm{S}$ knows that $\mathrm{Q}$. ${ }^{6}$

\footnotetext{
${ }^{5}$ We defend the reading of CS just presented in Roche and Roche (2017); see it for further details. We there appeal to some of Dretske's early work on contrastive focus (e.g., 1972, 1975, 1977) in order to make sense of his theory.

${ }^{6}$ See Baumann (2006), Dretske (2005a, 2005b, 2006a), Hawthorne (2005), Jäger (2004), Okasha (1999), Roche and Roche (2017), and Shackel (2006) for relevant discussion.
} 
It is well known that Dretske rejects Closure. Importantly, though, so that Closure is not an issue, Dretske grants for the sake of argument that if $\mathrm{S}$ knows that she thinks that $\mathrm{P}$, then she also knows that she thinks that P. This concession is compatible with CS, for CS concerns a way of knowing. Friends of Closure can thus also be friends of CS.

CS is admittedly quite odd. Setting aside the prominence of its author, is there any reason to care about it? We think there is, for it promises to solve two particularly challenging puzzles concerning self-knowledge. The first, which can be extracted from Dretske (2012a), is that while each of the following theses has some prima facie plausibility in isolation, they seem inconsistent as a set:

Privileged Self-Knowledge: There is a subject S and proposition $\mathrm{P}$ about her thoughts (e.g., the proposition that she thinks that $\mathrm{Q}$ ) such that $\mathrm{S}$ has a privileged way of knowing that $\mathrm{P}$.

Knowledge Requires Evidence: There is no subject $\mathrm{S}$ and proposition $\mathrm{P}$ such that $\mathrm{S}$ knows that $\mathrm{P}$ but has no adequate evidence for $\mathrm{P}$.

No Inner Awarenesses: There is no subject $\mathrm{S}$ and mental state/event $\mathrm{M}$ such that $\mathrm{S}$ is perceptually or quasi-perceptually aware of $\mathrm{M}^{7}$

It turns out, however, that if Dretske's defense of CS succeeds, then they are not inconsistent as a set. $\mathrm{CS}_{\mathrm{CO}}$ entails Privileged Self-Knowledge, and Dretske's defense of $\mathrm{CS}_{\mathrm{SK}}$ is based in part on Knowledge Requires Evidence and No Inner Awarenesses. ${ }^{8}$

How does Knowledge Requires Evidence fit into Dretske's general epistemology? The answer, in short, is that the latter should be understood so that $\mathrm{K}(\mathrm{S}, \mathrm{P}, \mathrm{A})$ holds only if $S$ 's evidence indicates that $P$ by ruling out, or enabling her to rule out, every member of $\mathrm{A}$ - the set of relevant alternatives at issue - except $\mathrm{P} .{ }^{9}$

\footnotetext{
${ }^{7}$ Although this puzzle is similar in some respects to the paradox introduced in Boghossian (1989), there are nonetheless important difference that in our opinion make the former more challenging than the latter. See Roche and Roche (2016) for further discussion of the former.

${ }^{8}$ Even if one finds one or more of the above theses implausible, Dretske's defense of CS is still interesting in that if it succeeds, the three theses are not inconsistent as a set.

${ }^{9}$ Dretske sometimes presents himself as a reliabilist on knowledge. But he stresses that he is not a process reliabilist, and that he accepts Knowledge Requires Evidence. See Dretske (2003b, pp. 11-12, n. 15, 2012a, p. 51, n. 3).
} 
The second puzzle that Dretske's theory promises to solve is McKinsey's paradox (McKinsey 1991). Here, first, Dretske explains the paradox (as he understands it):

Externalism about the mind - the metaphysical doctrine that thought and maybe even experience are constituted by extrinsic, relational facts about a person - is held to pose problems for how we can know, in the special authoritative way that we do, what is happening in our mind. ... Thought and experience cannot be relational, because if they were, people couldn't know, in the privileged way that they do, what they are thinking and experiencing. But people do know. So thought and experience are not relational. (Dretske 2003a, p. 131)

Here, next, he explains his proffered solution:

Enough about instruments. What does all this have to do with the mind? Well, the general drift should be obvious. If, like me, you think of the mind as the representational face of the brain and if, like me, you also understand representation in terms of informational functions, the conclusion will be evident enough: although we do not have information that we are representing the world - that we are thinking and experiencing - nonetheless, if we are representing it, if we are thinking and experiencing, we always have information about just how we are doing it, about the content of these mental states. If we think, we can know-in a privileged and authoritative way-what we think. What we can't know, at least not in the same authoritative way, is that we are thinking it. (Dretske 2003a, p. 136)

The rough idea here is straightforward. Dretske's externalism about the mind is consistent with CS. Given this, and given that CS implies Privileged Self-Knowledge, it follows that his externalism about the mind is consistent with Privileged SelfKnowledge. ${ }^{10,11}$

${ }^{10}$ In addition to his 2003a, see also his 2003c and 2006b. There are important respects in which Dretske's understanding of McKinsey's paradox is idiosyncratic. But whether or not CS solves McKinsey's paradox, Dretske's claim that his externalism is consistent with CS and therefore also with Privileged Self-Knowledge is of interest. See Sawyer (2015) for an alternative contrastivist answer to McKinsey's paradox. For general discussion of McKinsey's paradox, and for references, see Parent (2017).

${ }^{11} \mathrm{CS}$ is relevant to yet another puzzle concerning self-knowledge. Consider:

... some writers have worried that if one can know what one thinks, then one can know that one thinks. If so, then the ability to armchair know one's own thoughts would too easily refute eliminativism about the mental .... (Parent 2017, sec. 4, 
CS, if true, would thus be of great philosophical significance. Unfortunately, as we shall argue, Dretske's defense of CS fails. In Section 2, we explain Dretske's defense of CS (or certain key parts thereof). In Section 3, we argue (among other things) that if his defense of $\mathrm{CS}_{\mathrm{SK}}$ succeeds, then his defense of $\mathrm{CS}_{\mathrm{CO}}$ fails. In Section 4 and Section 5, we suggest a potential way forward. We suggest in particular that the correct way of being a Dretskean conciliatory skeptic is to deny that $\mathrm{S}$ has a privileged way of knowing about her thoughts, but to grant that she is nonetheless an authority on her thoughts. We also return briefly, in Section 5, to the two aforementioned puzzles (discussed in the main text).

\section{Dretske's defense of CS}

Dretske's defense of CS has two main parts: his defense of $\mathrm{CS}_{\mathrm{CO}}$ and his defense of $\mathrm{CS}_{\mathrm{SK}}$. We explain the former in Section 2.1 and the latter in Section 2.2.

\subsection{Dretske's defense of $\mathrm{CS}_{\mathrm{CO}}$}

Dretske distinguishes between "object-awareness" (hereafter "o-awareness") and "factawareness" (hereafter "f-awareness"). Here he explains both:

O-awareness ... is epistemically neutral. You can be o-aware of my cousin and not know he is my cousin. You can be aware of a kumquat and not know it is a kumquat. You can watch (see, be visually aware of) a robbery in progress and not know it is a robbery. You might think it is a perfectly routine transfer of money by bank officials. (Dretske 2012b, p. 4)

F-awareness, awareness of facts, is just another way of describing what someone knows. To be aware that I'm late is to know I'm late. To be aware that she is an expert is to know she is an expert. (Dretske 2012b, p. 4)

emphasis original)

CS says in part that S has no privileged, or "armchair", way of knowing the specific claim that she thinks that $\mathrm{P}$. It does not follow from this that $\mathrm{S}$ has no privileged way of knowing the general claim that, contra eliminativism, she has thoughts. But that is part of Dretske's overall view. He would deny that if $\mathrm{S}$ has a privileged way of knowing what she thinks, then she thereby has a privileged way of knowing that eliminativism is false. 
So f-awareness is knowledge (propositional knowledge) whereas o-awareness is not. ${ }^{12}$

The first passage makes clear that Dretske holds that there can be o-awarenesses of concrete objects. In fact, he holds that there can be o-awarenesses of abstract objects too. Consider:

We are not only o-aware of ordinary physical objects, events, and properties, but also of such abstract "objects" as (what philosophers call) propositions. They report on the TV news that it is snowing in Miami. I don't know they reported this on the news.

You now tell me that it is snowing in Miami. As a result of your communication, I am now o-aware of what they reported on the news - that it is snowing in Miamiwithout knowing it was reported on the TV news. This is o-awareness of a proposition, not f-awareness of a fact (the fact that it is snowing in Miami) because, as it turns out, there is no such fact. It isn't snowing in Miami. The TV news (and my informant) got it wrong. (Dretske 2012b, p. 7)

O-awareness of a proposition is important because Dretske holds that every thought (at least every occurrent conscious thought) involves an o-awareness of the proposition that is thought. S's thought that $\mathrm{P}$, for instance, involves an o-awareness of the proposition that $\mathrm{P} .^{13}$

This is central to Dretske's defense of $\mathrm{CS}_{\mathrm{CO}}$. He claims that S's o-awareness of the proposition that $\mathrm{P}$ gives her a privileged way of knowing that she thinks that $\mathrm{P}$; S's oawareness of $\mathrm{P}$ is the source of her privileged access. If he is correct, then, as per $\mathrm{CS}_{\mathrm{CO}}, \mathrm{S}$ has a privileged way of knowing that she thinks that $\mathrm{P}$.

Dretske says little, if anything, directly in support of the claim that S's o-awareness of the proposition that $\mathrm{P}$ gives her a privileged way of knowing that she thinks that $\mathrm{P}$. But consider this:

The Philosophical Gazette vows to publish all (and only) what I write. A truly dedicated vanity press! They tell me of their intentions. I believe them. I then write P. Given what they told me (they are completely trustworthy) I know they are going to publish P. How do I know that they are going to publish P? They told me. How do I

12 Dretske sometimes writes in terms of "acquaintance" instead of "o-awareness". See Dretske (2011, p. 429, 2012a, p. 56, 2012c, p. 157).

${ }^{13}$ How exactly an o-awareness of a proposition should be understood is unclear. But we are happy to bracket this issue and go along with Dretske's claim that we are often oaware of propositions. 
know what they are going to publish? By looking at what I write. Even if I cannot know what they will publish without knowing that they will publish it, my way of knowing the one is clearly different from my way of knowing the other. Observing myself write $\mathrm{P}$ is not my way of knowing that they will publish P. It is my way of

finding out what they will publish. (Dretske 2012b, p. 2)

His claim here, in part, is that his o-awareness (in the form of a visual experience) of his writing that $\mathrm{P}$ gives him a way of knowing - and is his way of knowing - that the Philosophical Gazette is going to publish that $\mathrm{P}$, even if it does not give him a way of knowing that the Philosophical Gazette is going to publish that P. Perhaps he thinks that if this is right, then, by analogy, S's o-awareness of the proposition that $\mathrm{P}$ gives her a way of knowing that she thinks that $\mathrm{P}$, even if it does not give her a way of knowing that she thinks that $\mathrm{P}$.

Some readers might regard as obvious that S's o-awareness of the proposition that $\mathrm{P}$ gives her a privileged way of knowing that she thinks that $\mathrm{P}$. After all, the contrastive focus indicates that the relevant alternatives at issue concern the content of S's thought, and $\mathrm{P}$ is that content. Keep in mind, though, that whether S's o-awareness does this depends on whether it gives her a way of ruling out each but the first member of the set: $\{\mathrm{S}$ thinks that $\mathrm{P}, \mathrm{S}$ thinks that $\mathrm{Q}, \mathrm{S}$ thinks that $\mathrm{R}, \ldots\}$.

We shall return to this issue in Section 3. First, though, we shall explain Dretske's defense of $\mathrm{CS}_{\mathrm{SK}}$.

\subsection{Dretske's defense of $\mathrm{CS}_{\mathrm{SK}}$}

A key part of Dretske's defense of $\mathrm{CS}_{\mathrm{SK}}$ is the following argument:

(1) S's o-awareness of the proposition that $\mathrm{P}$ gives her a privileged way of knowing that she thinks that $\mathrm{P}$ only if the proposition that $\mathrm{P}$ indicates that she thinks that $P$.

(2) The proposition that $\mathrm{P}$ does not indicate that $\mathrm{S}$ thinks that $\mathrm{P}$.

Thus

(3) S's o-awareness of the proposition that P does not give her a privileged way of knowing that she thinks that $P$.

This argument is obviously valid. But are (1) and (2) true? 
Dretske distinguishes between the ability to tell $\beta$ s from one another and the ability to tell that they are $\beta \mathrm{s}$. He explains this distinction by appeal to some examples:

I can easily distinguish my cousins from one another - they look much different - but as far as I can tell there is nothing about them that indicates they are my cousins. I can also tell Baptists from one another. This one is an old man, the other one a young woman; this one has freckles, the other a milky complexion. Once again, though, there is nothing about any of them (at least nothing I can see) that tells me they are Baptists. (Dretske 2012b, p. 9)

There is no explicit mention here of o-awarenesses. But the key point is that there can be cases where $S$ is o-aware of (for example, sees) some $\beta$ s, her o-awareness of the $\beta$ s in question enables her to distinguish between them, and yet, because the $\beta$ s have no $\beta$ indicating properties of which she is o-aware, her o-awareness of them does not enable her to tell-it does not give her a way of knowing - that they are $\beta$ s.

This point leads straightforwardly to (1). Yes, $\mathrm{S}$ is o-aware of the proposition that $\mathrm{P}$, and yes, this proposition (the proposition that $\mathrm{P}$ ) is a proposition that she thinks. But this is not enough to give her a way of knowing - let alone a privileged way of knowing that she thinks that $\mathrm{P}$. It needs to be the case that the proposition that $\mathrm{P}$ indicates that she thinks that P. Hence, as per (1), S's o-awareness of the proposition that $\mathrm{P}$ gives her a privileged way of knowing that she thinks that $\mathrm{P}$ only if the proposition that $\mathrm{P}$ indicates that she thinks that $\mathrm{P}$.

We noted in Section 1 that Dretske's defense of $\mathrm{CS}_{\mathrm{SK}}$ is based in part on Knowledge Requires Evidence. We had in mind there, among other things, (1) and his defense of it. His thought here is that if the proposition that $\mathrm{P}$ does not indicate that $\mathrm{S}$ thinks that $\mathrm{P}$, then S's o-awareness of the proposition that $\mathrm{P}$ is not (and does not give her) adequate evidence for the proposition that she thinks that $\mathrm{P}$, and thus does not give her a way of knowing that she thinks that $\mathrm{P}$.

Why believe, as per (2), that the proposition that $\mathrm{P}$ does not indicate that $\mathrm{S}$ thinks that P? Consider the following:

It is important to understand that if what one thinks (the content of the thought) is regarded as a property of the thought, it is not an indicator property. Propositionswhat is reported, published, written, said, and thought - do not indicate anything at all. They are evidentially worthless. There is nothing about what they report on the TV news - that it is snowing in Miami - that indicates it was reported on the TV news. There is nothing about what the Philosophical Gazette publishes that indicates they publish it. There is nothing about what a person says that indicates he said it. 
There is, finally, nothing about what you think that indicates you think it. What you think or say indicates nothing because (unlike a fact) what you think or say needn't be true. If it was a fact that it is snowing in Miami, that might indicate that the snowfall was reported on the TV news. The TV news is, after all, a reliable source of information about unusual events. So if it was snowing in Miami you can bet money they reported it. But the proposition (indeterminate truth value) that it is snowing in Miami does not indicate anything. That is why awareness of it-awareness, simply, of what they reported on the news - is of absolutely no help in finding out whether it was reported on the news. (Dretske 2012b, p. 10)

The idea here is that because a proposition need not be true, it indicates nothing. Thus, what you think - a proposition - does not indicate that you think it. It follows then that, as per (2), the proposition that $\mathrm{P}$ does not indicate that $\mathrm{S}$ thinks that $\mathrm{P}$.

There is more to Dretske's defense of $\mathrm{CS}_{\mathrm{SK}}$ than his argment for (3). We shall return to some of this, but, for now, the foregoing will suffice for our purposes.

\section{Our critique}

There appears to be a tension between Dretske's defense of $\mathrm{CS}_{\mathrm{CO}}$ and his defense of $\mathrm{CS}_{\mathrm{SK}}$. The former claims that S's o-awareness of $\mathrm{P}$ gives her a privileged way of knowing that she thinks that $\mathrm{P}$. The latter claims that propositions indicate nothing. But if propositions are evidentially worthless in this way, how can S's o-awareness of $\mathrm{P}$ give her a way of knowing - let alone a privileged way of knowing - that she thinks that $\mathrm{P}$ ? Indeed, how can it give her a way of knowing anything?

Perhaps Dretske is guilty of engaging in hyperbole in the previous quotation. Perhaps propositions indicate very little, but not nothing. The following remark from Dretske seems to support this possibility:

It would ... be a mistake to view introspection as a form of inner sense, as a perception-like awareness of one's own thoughts. [S] is aware of her own thoughts, yes, but unlike the (often) revealing aspects of ordinary objects (trees, people, automobiles, houses), the aspect of her thought she is aware of, its content, does not disclose, indicate, or reveal that it is the content of a thought. It does not indicate or reveal anything at all except (see footnote 11) what it is she is thinking. (Dretske 2012a, p. 59, emphasis added)

The italicized part of this passage seems to allow that $\mathrm{P}$ - "the aspect of [S's] thought she is aware of"-indicates at least one thing, viz., that she thinks that P. This is the only 
passage in Dretske's writings (as far as we are aware) where he explicitly qualifies his claim that propositions are evidentially worthless. Even so, is there something to it?

No. To see why, suppose (as is perfectly reasonable) that you, like $S$, know that $S$ is thinking, ${ }^{14}$ and that you, like $\mathrm{S}$, are o-aware of the proposition that $\mathrm{P}$, because you, like $\mathrm{S}$, are thinking that $\mathrm{P}$. If the qualification in question were true, then your o-awareness of the proposition that $\mathrm{P}$ would give you a way of knowing that $S$ thinks that $\mathrm{P}$. Clearly, though, this is not the case. For, your o-awareness does not enable you to rule out the alternative that $\mathrm{S}$ thinks that $\mathrm{Q}$, or any other alternative to the proposition that $\mathrm{S}$ thinks that $\mathrm{P}$.

Our argument does not assume that if $\mathrm{S}$ and you are both o-aware of a certain object, then S's o-awareness enables her to come to know a particular proposition only if your oawareness enables you to come to know that very same proposition. Such an assumption is doubtful, for you and $\mathrm{S}$ might be sufficiently different from each other in terms of relevant background knowledge. If so, then S's o-awareness might enable her to come to know the proposition in question whereas your o-awareness does not. For this reason, our argument assumes that you and $\mathrm{S}$ are the same in the relevant piece of background knowledge: S knows that she is thinking, and you know that S is thinking. Hence, S's oawareness enables her to rule out each of the relevant alternatives only if your oawareness enables you to rule out each of those alternatives. Because your o-awareness does not enable you to do this, neither does hers. This is our point.

Perhaps returning to the case of the Philosophical Gazette will be helpful here. Recall that Dretske's o-awareness of what he writes gives him knowledge that the Philosophical Gazette will publish that P. We noted in Section 2.1 that perhaps he thinks that if he is right about this, then, by analogy, he is right that S's o-awareness of the proposition that $\mathrm{P}$ gives her a way of knowing that she thinks that $\mathrm{P}$. There is a crucial disanalogy between these cases, however. In the case of Dretske and the Philosophical Gazette, Dretske's o-awareness is an o-awareness of an event (his writing that P), not a proposition (such as the proposition that he is writing that $\mathrm{P}$ ). In the case of $\mathrm{S}$ and her thought that $\mathrm{P}$, by contrast, $\mathrm{S}$ 's o-awareness is an o-awareness of a proposition (the proposition that $\mathrm{P}$ ), not an event (such as the event of her becoming o-aware of the proposition that $\mathrm{P})$.

\footnotetext{
${ }^{14}$ Recall that for the purpose of setting aside issues of closure, Dretske concedes that $\mathrm{S}$ knows that she thinks that $\mathrm{P}$ only if she knows that she thinks that $\mathrm{P}$. We suspect that for the same reason, he would concede that you know that $\mathrm{S}$ thinks that $\mathrm{P}$ only if you know that she thinks that $\mathrm{P}$. This is why we are supposing that you know she is thinking.
} 
The situation would perhaps be importantly different if S were o-aware of her oawareness of the proposition that $\mathrm{P}$. If she were, then perhaps this would enable her to come to know that she thinks that $\mathrm{P} .{ }^{15}$ But recall Dretske's adherence to No Inner Awarenesses (the thesis that there is no subject $\mathrm{S}$ and mental state/event $\mathrm{M}$ such that $\mathrm{S}$ is perceptually or quasi-perceptually aware of $\mathrm{M}$ ). If he is right here, then there are no oawarenesses of o-awarenesses, and thus $\mathrm{S}$ is not o-aware of her o-awareness of the proposition that $\mathrm{P} .^{16}$

The lesson in all this is that Dretske's defense of CS is hopelessly problematic. His defense of $\mathrm{CS}_{\mathrm{SK}}$ relies on the claim that propositions are evidentially worthless in that they indicate nothing, and so S's o-awareness of the proposition that $\mathrm{P}$ fails to give her a way of knowing that she thinks that $\mathrm{P}$. But then his defense of $\mathrm{CS}_{\mathrm{CO}}$ fails, for S's oawareness of the proposition that $\mathrm{P}$ also fails to give her a way of knowing that she thinks that $\mathrm{P}$. Hence if Dretske's defense of $\mathrm{CS}_{\mathrm{SK}}$ succeeds, then his defense of $\mathrm{CS}_{\mathrm{CO}}$ fails.

It does not follow, however, that if Dretske's defense of $\mathrm{CS}_{\mathrm{SK}}$ succeeds, then $\mathrm{CS}_{\mathrm{CO}}(a$ thesis) is false. It is highly plausible, though, that in fact this is the case. In Section 2.2, we noted that there is more to Dretske's defense of $\mathrm{CS}_{\mathrm{SK}}$ than his argument for (3). We had in mind in part his argument for the following:

${ }^{15}$ Imagine, e.g., that $\mathrm{S}$ can be o-aware of at most one proposition at a time (and that $\mathrm{S}$ knows this). Then, if $\mathrm{S}$ knows she is thinking, she can deduce that she is thinking that $\mathrm{P}$.

${ }^{16}$ Dretske references a footnote in the passage displayed at the beginning of this section where he qualfies his claim about the evidential worth of propositions. It reads in part:

You do not have to know (be aware that) $p$ and $q$ are propositions to be aware of, and thereby distinguish, $p$ from $q$ anymore than you have to be aware (know) that $\mathrm{X}$ and $\mathrm{Y}$ are counterfeit to be visually aware of, and thereby distinguish, $\mathrm{X}$ (the $\$ 100$ counterfeit bill) from Y (the $\$ 50$ counterfeit bill). (Dretske 2012a, p. 57, fn. 11)

We fail to see how this supports $\mathrm{CS}_{\mathrm{CO}}$. S's being able to distinguish between the proposition that $\mathrm{P}$ and the proposition that $\mathrm{Q}$ is one thing. S's being able to rule out the proposition that she thinks that $\mathrm{Q}$ is another thing entirely. (Recall Dretske's point about being able to distinguish between Baptists even though nothing about them indicates that they are Baptists.) You too can distinguish between the proposition that $\mathrm{P}$ and the proposition that $\mathrm{Q}$, but you are not thereby in a position to rule out the proposition that $\mathrm{S}$ thinks that Q. 
(4) S has a privileged way of knowing that she thinks that $\mathrm{P}$ only if she is o-aware of things of which others cannot ${ }^{17}$ be o-aware.

We also had in mind No Inner Awarenesses. If, as it seems, No Inner Awarenesses implies that $\mathrm{S}$ is not o-aware of things of which others cannot be o-aware, then by (4) it follows that $\mathrm{S}$ has no privileged way of knowing that she thinks that $\mathrm{P}$.

Now consider the following variant of (4):

$\left(4^{*}\right) \quad \mathrm{S}$ has a privileged way of knowing that she thinks that $\mathrm{P}$ only if she is o-aware of things of which others cannot be o-aware.

Dretske's argument for (4) carries over to (4*). Hence, if his argument for (4) succeeds, and if No Inner Awarenesses implies that $\mathrm{S}$ is not o-aware of things of which others cannot be o-aware, then by $\left(4^{*}\right)$ it follows that, contra $\mathrm{CS}_{\mathrm{CO}}, \mathrm{S}$ has no privileged way of knowing that she thinks that $\mathrm{P}$.

A second lesson thus emerges. Given Dretske's commitment to No Inner Awarenesses, and given his understanding of privileged knowledge (along with his understanding of the relation between evidence and knowledge more generally), it follows that $\mathrm{CS}_{\mathrm{CO}}$ itself is false.

In sum, we have argued that Dretske's defense of $\mathrm{CS}_{\mathrm{SK}}$ undermines both his defense of $\mathrm{CS}_{\mathrm{CO}}$ and $\mathrm{CS}_{\mathrm{CO}}$ itself. The conciliatory side of $\mathrm{CS}$ is thus doubly problematic; its failure is overdetermined. This is not the end of the line for Dretskean conciliatory skeptics, however. We turn now to a potential way forward.

\section{Authority without privilege}

There are serious problems with the conciliatory side of CS. But might Dretskeans have available to them a weaker surrogate to privileged knowledge? It seems so. Dretske (2012c) introduces a sense of authority that is independent of privileged knowledge.

${ }^{17}$ The kind of modality that Dretske has in mind here is unclear. Is it logical, technological, or something in between? Notice that a similar question arises with respect to CS. Recall that, for Dretske, $\mathrm{S}$ has a privileged way of knowing a given fact only if she has a way of knowing it that is unavailable to others. We assume that whatever kind of modality he has in mind for the latter, he has in mind for the former. 
He gives a case involving a young child named Sarah who lacks the concept of thought and so has no knowledge of, let alone privileged knowledge of, her thoughts. He claims that she is nonetheless an authority on what she thinks. He writes:

She is an authority on what she thinks in the sense that if we want to find out what Sarah thinks, we have to "consult" her. We cannot, of course, do so by asking Sarah what she thinks. She will not (we are assuming) understand what we are talking about. But there are other ways of getting this information. Given a cooperative child, we can ask Sarah whether her father is home. Or why she is rushing to open the door. The answers will reveal, reliably enough for us to know what she is thinking, what she thinks. If Sarah was not aware of what she thinks as she rushes to the door, how could she (not her mother or anyone else) be the authority on why she is running to the door? (Dretske 2012c, pp. 159-160, emphasis added)

The rough idea here is clear enough. If you ask Sarah whether her father is home, and she answers in the affirmative, then her answer indicates that - it reveals the fact that - she thinks that her father is home. (We qualify this point about indication shortly.) If, instead, you put the question to her mother, and her mother answers in the affirmative, then her mother's answer does not indicate that — it does not reveal the fact that — Sarah thinks that her father is home. ${ }^{18}$ Sarah is thus an authority on whether she thinks that her father is home in that, though she lacks the concept of thought and so has no knowledge of her thoughts, she is the person to consult to find out whether she thinks that her father is home.

It might seem strange to speak of Sarah as an authority on whether she thinks that her father is home, and on what she thinks more generally, given that she lacks the concept of thought and so has no knowledge of her thoughts. Consider, though, by way of analogy, the question of what to consult to find out whether your car's gas tank is full. The answer, clearly, is that you should consult your car's gas gauge (assuming that you cannot directly examine the tank). This is not because of the gauge's knowledge of the amount of gas in the tank; the gauge, of course, has no such knowledge. The gauge is the thing to consult, and thus is an "authority" in the sense in question, because it (and, suppose, it alone) is connected to the tank in such a way that if it reads "Full", then this indicates that in fact the tank is full.

${ }^{18}$ Notice that Sarah's mother's affirmative answer to the question "does Sarah think that her father is home?" also fails to indicate that Sarah thinks that her father is home. Sarah's behavior could be misleading, after all. 
Dretske's points about Sarah are meant to generalize to subjects who, unlike Sarah, have the concept of thought. Return to $\mathrm{S}$ and her thought that $\mathrm{P}$, and take some subject $\mathrm{S}$ * distinct from $\mathrm{S}$. If $\mathrm{S}$ is asked whether $\mathrm{P}$, and she answers in the affirmative, then her answer indicates that she thinks that $\mathrm{P}$. If, in contrast, $\mathrm{S}^{*}$ is asked whether $\mathrm{P}$, and he answers in the affirmative, then his answer does not indicate that $\mathrm{S}$ thinks that $\mathrm{P}$. Hence $\mathrm{S}$ is the person to consult to find out whether she thinks that $\mathrm{P}$, and is in this sense an authority - the authority-on whether she thinks that ${ }^{19}$

Are these claims meant to hold in all cases? The answer, we take it, is negative. Dretske has in mind typical, or realistic, cases. These are cases where:

(5) $\mathrm{S}$ and $\mathrm{S}^{*}$ 's affirmative answers to the question of whether $\mathrm{P}$ are sincere, based on an adequate understanding of the question, and so on.

(6) $\mathrm{S}^{*}$ 's thinking that $\mathrm{P}$ does not indicate that $\mathrm{S}$ thinks that $\mathrm{P}^{20}$

When (5) holds, S's affirmative answer to the question of whether P expresses her underlying thought. And when this happens, her answer thereby indicates that she thinks that $\mathrm{P}$. If, say, she had thought that not-P rather than thought that $\mathrm{P}$, then, given (5), she would not have answered in the affirmative. Similarly, when (5) holds, S*'s affirmative answer to the question of whether $\mathrm{P}$ expresses his underlying thought. And when this happens, his answer thereby indicates that he thinks that P. However, as per (6), it is not the case that his answer indicates that $\mathrm{S}$ thinks that $\mathrm{P}$, since, in part, it is not the case that

${ }^{19}$ These points are related to a well-known passage from Evans (1982):

I get myself in a position to answer the question whether I believe that $p$ by putting into operation whatever procedure I have for answering the question whether $p$.... If a judging subject applies this procedure, then necessarily he will gain knowledge of one of his own mental states: even the most determined sceptic cannot find here a gap in which to insert his knife. (Evans 1982, p. 225)

The idea that Evans's procedure is knowledge-yielding arguably runs counter to Knowledge Requires Evidence. If so, and if that thesis is true, then there is a gap in which a skeptic can insert his knife! But, regardless, Evans's procedure is reliable. Evans-style approaches to the epistemology of belief are defended by, among others, Byrne (2018, Ch. 5), Fernandez (2013, Ch. 2), and Roche (2016).

${ }^{20}$ Cases can be described where $\mathrm{S}^{*}$ 's thinking that $\mathrm{P}$ does indicate that $\mathrm{S}$ thinks that $\mathrm{P}$ (imagine, e.g., that $\mathrm{S}$ and $\mathrm{S}^{*}$ have minds that are for whatever reason perfectly in sync with one another). When (6) holds — as it typically will—such cases are ruled out. 
his answer expresses her underlying thought. The aforementioned indication asymmetry is thus grounded in an asymmetry concerning expression.

You will of course most often (if not always) be unsure whether (5) holds. Does such uncertainty undermine the sense in which $\mathrm{S}$ is an authority concerning whether she thinks that P? Not if certain rather natural conditions hold. Let A, B, C, and D be understood as follows:

A: $S$ thinks that $\mathrm{P}$.

B: You ask $\mathrm{S}$ whether $\mathrm{P}$, and she answers in the affirmative.

$\mathrm{C}: \mathrm{S}^{*}$ thinks that $\mathrm{P}$.

D: You ask $\mathrm{S}^{*}$ whether $\mathrm{P}$, and he answers in the affirmative.

Suppose that your credence in A given B should be the same as your credence in $\mathrm{C}$ given $\mathrm{D}$, and that, because you are not sure that (5) is true, neither of these credences should be equal to one:

(7) $\quad 1>\operatorname{Pr}(\mathrm{A} \mid \mathrm{B})=\operatorname{Pr}(\mathrm{C} \mid \mathrm{D})$.

Suppose, next, that your credence in A given B should be greater than your credence in A given $\mathrm{C}$, and that your credence in $\mathrm{A}$ given $\mathrm{C}$, in turn, should be greater than your credence in A:

$$
\operatorname{Pr}(\mathrm{A} \mid \mathrm{B})>\operatorname{Pr}(\mathrm{A} \mid \mathrm{C})>\operatorname{Pr}(\mathrm{A}) .
$$

Suppose, finally, that D should have no impact on your credence in A given $\mathrm{C}$ or on your credence in A given $\sim \mathrm{C}$ :

$$
\operatorname{Pr}(\mathrm{A} \mid \mathrm{C} \& \mathrm{D})=\operatorname{Pr}(\mathrm{A} \mid \mathrm{C}) \text { and } \operatorname{Pr}(\mathrm{A} \mid \sim \mathrm{C} \& \mathrm{D})=\operatorname{Pr}(\mathrm{A} \mid \sim \mathrm{C}) .^{21}
$$

It turns out, as shown in the appendix, that (7), (8), and (9) together entail that your credence in A given B should be greater than your credence in A given D:

(10) $\operatorname{Pr}(\mathrm{A} \mid \mathrm{B})>\operatorname{Pr}(\mathrm{A} \mid \mathrm{D})$.

This is true even if $\operatorname{Pr}(\mathrm{A} \mid \mathrm{B})$, and thus also $\operatorname{Pr}(\mathrm{C} \mid \mathrm{D})$, is less than 0.5. Here too, then, even though S's answer to the question of whether $\mathrm{P}$ would not enable you to come to know

${ }^{21}$ This is a "screening-off" condition to the effect that each member of partition $\Gamma=\{\mathrm{C}$, $\sim$ C r renders D probabilistically irrelevant to A. For recent discussion of screening-off, and for references, see, e.g., Roche (2017) and Shogenji (2017). 
whether she thinks that $\mathrm{P}$ (at least not on Dretske's epistemology), there is a clear sense in which $\mathrm{S}$ is an authority on whether she thinks that $\mathrm{P}^{22}$

The foregoing suggests that $\mathrm{S}$ is an authority on whether she thinks that $\mathrm{P}$. Does her authority extend even further, though? Specifically, when authority is a matter of the person to consult (as spelled out in this section), is $\mathrm{S}$ an authority on whether she thinks that P?

It seems so. Take (5) and the following variant of (6):

(6*) $\quad \mathrm{S}^{*}$ 's thinking that $\mathrm{P}$ does not indicate that $\mathrm{S}$ thinks that $\mathrm{P}$.

When (5) holds, S's affirmative answer to the question of whether P expresses her underlying thought. And when this happens, her answer thereby indicates that she thinks that P. If, say, she had suspended judgment on whether $\mathrm{P}$ rather than thought that $\mathrm{P}$, then she would not have answered in the affirmative. Similarly, when (5) holds, S*'s affirmative answer to the question of whether $\mathrm{P}$ expresses his underlying thought. And when this happens, his answer thereby indicates that he thinks that P. But, given (6*) in part, his answer does not indicate that $\mathrm{S}$ thinks that $\mathrm{P}$.

There is more. The point above that (7), (8), and (9) together entail (10) holds regardless of whether the issue is whether $\mathrm{S}$ thinks that $\mathrm{P}$ or is instead the issue of whether $\mathrm{S}$ thinks that $\mathrm{P}$.

In sum, $\mathrm{S}$ is an authority (in the way spelled out in this section) both on whether she thinks that $\mathrm{P}$ and on whether she thinks that $\mathrm{P}$. The foregoing thus makes the case for a fully conciliatory theory concerning authority of one's thoughts. Moreover, notice that the case for this requires no assumption that $\mathrm{S}$ has a privileged way of knowing her thoughts. Even if S has no privileged way of knowing about her thoughts, and even if she

${ }^{22}$ The literature on confabulation suggests one way in which $\operatorname{Pr}(\mathrm{A} \mid \mathrm{B})$ might be less than 0.5. Perhaps $S$ will sometimes sincerely assert that $P$, not because she thinks that $P$, but rather because she confabulates. (Although confabulation is typically taken to involve a self-ascription of a mental state, asserting that $\mathrm{P}$ is true is closely related to asserting that one thinks that $\mathrm{P}$ (Evans 1982)). Suppose, for example, that $\mathrm{S}$ is motivated to believe that she thinks that P (and thus to assert that P). Take the "and so on" in (5) to include the condition that $\mathrm{S}$ is not confabulating in this way. The current point is that even if you are unsure whether (5) holds, $\mathrm{S}$ is still the authority on whether she thinks that $\mathrm{P}$ in that $\operatorname{Pr}(\mathrm{A}$ | B) $>\operatorname{Pr}(\mathrm{A} \mid \mathrm{D})$. For discussion of confabulation studies, and for references, see Schwitzgebel (2016, sec. 4). We thank an anonymous reviewer for pointing out the relevance of confabulation to our project. 
has no knowledge whatsoever of her thoughts, she is still the person to consult to find out about her thoughts. Think, again, of Sarah and her thought that Daddy is home. ${ }^{23}$

\section{How to be a Dretskean conciliatory skeptic}

We suggest, then, that Dretskean conciliatory skeptics adopt a fully conciliatory theory concerning authority: they should hold not just that $\mathrm{S}$ is an authority on whether she thinks that $\mathrm{P}$, but also that $\mathrm{S}$ is an authority on whether she thinks that $\mathrm{P} .{ }^{24} \mathrm{We}$ also suggest that they adopt a fully skeptical theory concerning privileged knowledge: they should hold not just that $\mathrm{S}$ has no privileged way of knowing that she thinks that $\mathrm{P}$, but also that she has no privileged way of knowing that she thinks that $\mathrm{P}$. The overall viewa conjunction of both a fully conciliatory theory concerning authority and a fully skeptical theory concerning privileged knowledge — would still have both a conciliatory side and a skeptical side, and it would still be grounded in Dretske's general epistemological and metaphysical commitments (his contrastivist epistemology, No Inner Awarenesses, etc.). Further, and crucially, it might well be true. Let "CS*" refer to this new view.

We return now briefly to the two puzzles described in the main text of Section 1. CS promised to solve these puzzles. How does CS* fare? Consider, first, the puzzle consisting of Privileged Self-Knowledge, Knowledge Requires Evidence, and No Inner Awarenesses. Given that $\mathrm{CS}^{*}$ is fully skeptical concerning privileged knowledge, Dretskeans can simply reject Privileged Self-Knowledge while keeping Knowledge Requires Evidence and No Inner Awarenesses. And given that CS* is fully conciliatory

${ }^{23}$ We claimed above that when (5) holds, S's affirmative answer to the question of whether $\mathrm{P}$ expresses her underlying thought that $\mathrm{P}$. This is central to the foregoing account of authority. The account has this in common with "neo-expressivist" accounts of first-person authority (Bar-On 2004 and Finkelstein 2003). There is also a difference, however. Neo-expressivists focus on avowals, i.e., utterances such as "I think that P". Our account, by contrast, focuses on utterances such as "Yes, P", which make no mention of thought or even a thinking subject. The former semantically express propositions that ascribe mental states; the latter do not.

${ }^{24}$ They can even add in a second conciliatory thesis to the effect that $\mathrm{S}$ has both a nonprivileged way of knowing that she thinks that $\mathrm{P}$, and a non-privileged way of knowing that she thinks that $\mathrm{P}$. 
concerning authority, Dretskeans can stress that such authority, though not as ambitious as Privileged Self-Knowledge, is a worthy (and not false!) fall back position.

What about McKinsey's paradox? Dretskeans can trade in Dretske's point that his externalism about the mind is consistent with CS and thus with Privileged SelfKnowledge for the point that his externalism about the mind is consistent with CS*'s fully conciliatory stance on authority. Dretskeans could then argue that this is enough to answer McKinsey's paradox.

We are not claiming, of course, that the suggested replacement theory- $\mathrm{CS} *$-will prove to be a satisfactory theory in the end. But, we suggest, it at least merits careful consideration. We are claiming, however, that the correct way of being a Dretskean conciliatory skeptic is to move from CS to $\mathrm{CS}^{*}{ }^{25}$

\section{Appendix}

Suppose that:

$$
\begin{aligned}
& 1>\operatorname{Pr}(\mathrm{A} \mid \mathrm{B})=\operatorname{Pr}(\mathrm{C} \mid \mathrm{D}) . \\
& \operatorname{Pr}(\mathrm{A} \mid \mathrm{B})>\operatorname{Pr}(\mathrm{A} \mid \mathrm{C})>\operatorname{Pr}(\mathrm{A})>0 . \\
& \operatorname{Pr}(\mathrm{A} \mid \mathrm{C} \& \mathrm{D})=\operatorname{Pr}(\mathrm{A} \mid \mathrm{C}) \text { and } \operatorname{Pr}(\mathrm{A} \mid \sim \mathrm{C} \& \mathrm{D})=\operatorname{Pr}(\mathrm{A} \mid \sim \mathrm{C}) .
\end{aligned}
$$

The aim is to show that:

$$
\operatorname{Pr}(\mathrm{A} \mid \mathrm{B})>\operatorname{Pr}(\mathrm{A} \mid \mathrm{D}) \text {. }
$$

It follows from the law of total probability that:

$$
\operatorname{Pr}(\mathrm{A} \mid \mathrm{D})=\operatorname{Pr}(\mathrm{C} \mid \mathrm{D}) \operatorname{Pr}(\mathrm{A} \mid \mathrm{C} \& \mathrm{D})+\operatorname{Pr}(\sim \mathrm{C} \mid \mathrm{D}) \operatorname{Pr}(\mathrm{A} \mid \sim \mathrm{C} \& \mathrm{D}) .
$$

Given this, and given (7) and (9), it follows that:

$$
\begin{aligned}
& \operatorname{Pr}(\mathrm{A} \mid \mathrm{D})=\operatorname{Pr}(\mathrm{A} \mid \mathrm{B}) \operatorname{Pr}(\mathrm{A} \mid \mathrm{C} \& \mathrm{D})+\operatorname{Pr}(\sim \mathrm{A} \mid \mathrm{B}) \operatorname{Pr}(\mathrm{A} \mid \sim \mathrm{C} \& \mathrm{D}) \\
& \quad=\operatorname{Pr}(\mathrm{A} \mid \mathrm{B}) \operatorname{Pr}(\mathrm{A} \mid \mathrm{C})+\operatorname{Pr}(\sim \mathrm{A} \mid \mathrm{B}) \operatorname{Pr}(\mathrm{A} \mid \sim \mathrm{C}) \\
& \quad=\operatorname{Pr}(\mathrm{A} \mid \mathrm{B}) \operatorname{Pr}(\mathrm{A} \mid \mathrm{C})+\operatorname{Pr}(\mathrm{A} \mid \sim \mathrm{C})-\operatorname{Pr}(\mathrm{A} \mid \mathrm{B}) \operatorname{Pr}(\mathrm{A} \mid \sim \mathrm{C}) .
\end{aligned}
$$

It follows from this and (8) that:

\footnotetext{
${ }^{25}$ We thank two reviewers at this journal for their helpful comments. We also thank Sarah Paul for feedback on an earlier version of this paper.
} 
(13)

$$
\begin{aligned}
& \operatorname{Pr}(\mathrm{A} \mid \mathrm{B}) \operatorname{Pr}(\mathrm{A} \mid \mathrm{B})+\operatorname{Pr}(\mathrm{A} \mid \sim \mathrm{C})-\operatorname{Pr}(\mathrm{A} \mid \mathrm{B}) \operatorname{Pr}(\mathrm{A} \mid \sim \mathrm{C})> \\
& \operatorname{Pr}(\mathrm{A} \mid \mathrm{B}) \operatorname{Pr}(\mathrm{A} \mid \mathrm{C})+\operatorname{Pr}(\mathrm{A} \mid \sim \mathrm{C})-\operatorname{Pr}(\mathrm{A} \mid \mathrm{B}) \operatorname{Pr}(\mathrm{A} \mid \sim \mathrm{C})= \\
& \operatorname{Pr}(\mathrm{A} \mid \mathrm{D}) .
\end{aligned}
$$

The following holds without exception:

$$
\begin{aligned}
& \operatorname{Pr}(\mathrm{A} \mid \mathrm{B})>\operatorname{Pr}(\mathrm{A} \mid \mathrm{B}) \operatorname{Pr}(\mathrm{A} \mid \mathrm{B})+\operatorname{Pr}(\mathrm{A} \mid \sim \mathrm{C})-\operatorname{Pr}(\mathrm{A} \mid \mathrm{B}) \operatorname{Pr}(\mathrm{A} \mid \sim \mathrm{C}) \text { iff } \\
& \operatorname{Pr}(\mathrm{A} \mid \mathrm{B})-\operatorname{Pr}(\mathrm{A} \mid \mathrm{B}) \operatorname{Pr}(\mathrm{A} \mid \mathrm{B})>\operatorname{Pr}(\mathrm{A} \mid \sim \mathrm{C})-\operatorname{Pr}(\mathrm{A} \mid \mathrm{B}) \operatorname{Pr}(\mathrm{A} \mid \sim \mathrm{C}) \text { iff } \\
& \operatorname{Pr}(\mathrm{A} \mid \mathrm{B})[1-\operatorname{Pr}(\mathrm{A} \mid \mathrm{B})]>\operatorname{Pr}(\mathrm{A} \mid \sim \mathrm{C})[1-\operatorname{Pr}(\mathrm{A} \mid \mathrm{B})] \text { iff } \\
& \operatorname{Pr}(\mathrm{A} \mid \mathrm{B})>\operatorname{Pr}(\mathrm{A} \mid \sim \mathrm{C}) .
\end{aligned}
$$

Given this, and given that (8) entails that $\operatorname{Pr}(\mathrm{A} \mid \mathrm{B})>\operatorname{Pr}(\mathrm{A} \mid \sim \mathrm{C})$, it follows that:

$$
\operatorname{Pr}(\mathrm{A} \mid \mathrm{B})>\operatorname{Pr}(\mathrm{A} \mid \mathrm{B}) \operatorname{Pr}(\mathrm{A} \mid \mathrm{B})+\operatorname{Pr}(\mathrm{A} \mid \sim \mathrm{C})-\operatorname{Pr}(\mathrm{A} \mid \mathrm{B}) \operatorname{Pr}(\mathrm{A} \mid \sim \mathrm{C}) .
$$

By (13) and (15) it follows that (10) holds. QED

\section{References}

Aydede, M. (2003). Is introspection inferential? In B. Gertler (Ed.), Privileged access: Philosophical accounts of self-knowledge (pp. 55-64). Burlington: Ashgate.

Bar-On, D. (2004). Speaking my mind: Expression and self-knowledge. Oxford: Oxford University Press.

Baumann, P. (2006). Information, closure, and knowledge: On Jäger's objection to Dretske. Erkenntnis, 64, 403-408.

Blaauw, M. (2008). Contesting Pyrrhonian contrastivism. Philosophical Quarterly, 58, 471-477.

Boghossian, P. (1989). Content and self-knowledge. Philosophical Topics, 17, 5-26.

Byrne, A. (2018). Transparency and self-knowledge. New York: Oxford University Press.

Dretske, F. (1970). Epistemic operators. Journal of Philosophy, 67, 1007-1023.

Dretske, F. (1971). Conclusive reasons. Australasian Journal of Philosophy, 49, 1-22.

Dretske, F. (1972). Contrastive statements. Philosophical Review, 81, 411-437. 
Dretske, F. (1975). The content of knowledge. In B. Freed, A. Marras, and P. Maynard (Eds.), Forms of representation (pp. 77-93). Amsterdam: North-Holland.

Dretske, F. (1977). Referring to events. Midwest Studies in Philosophy, 2, 90-99.

Dretske, F. (1981a). Knowledge and the flow of information. Cambridge (MA): MIT Press.

Dretske, F. (1981b). The pragmatic dimension of knowledge. Philosophical Studies, 40, 363-378.

Dretske, F. (1994). Introspection. Proceeding of the Aristotelian Society, 94, 263-278.

Dretske, F. (1995). Naturalizing the mind. Cambridge (MA): MIT Press.

Dretske, F. (1999). The mind's awareness of itself. Philosophical Studies, 95, 103-124.

Dretske, F. (2003a). Externalism and self-knowledge. In S. Nuccetelli (Ed.), New essays on semantic externalism and self-knowledge (pp. 131-142). Cambridge (MA): MIT Press.

Dretske, F. (2003b). How do you know you are not a zombie? In B. Gertler (Ed.), Privileged access: Philosophical accounts of self-knowledge (pp. 1-13). Burlington: Ashgate.

Dretske, F. (2003c). Knowing what you think vs. knowing that you think. In R. Schantz (Ed.), The externalist challenge: New studies on cognition and intentionality (pp. 389-400). Berlin: Walter de Gruyter.

Dretske, F. (2005a). The case against closure. In M. Steup and E. Sosa (Eds.), Contemporary debates in epistemology (pp. 13-26). Malden: Blackwell.

Dretske, F. (2005b). Reply to Hawthorne. In M. Steup and E. Sosa (Eds.), Contemporary debates in epistemology (pp. 43-46). Malden: Blackwell.

Dretske, F. (2006a). Information and closure. Erkenntnis, 64, 409-413.

Dretske, F. (2006b). Representation, teleosemantics, and the problem of self-knowledge. In G. Macdonald and D. Papineau (Eds.), Teleosemantics (pp. 69-84). New York: Oxford University Press.

Dretske, F. (2011). Skeptical doubts about self-knowledge. In S. Bernecker and D. Pritchard (Eds.), The Routledge companion to epistemology (pp. 425-432). New York: Routledge. 
Dretske, F. (2012a). Awareness and authority: Skeptical doubts about self-knowledge. In D. Smithies and D. Stoljar (Eds.), Introspection and consciousness (pp. 49-64). Oxford: Oxford University Press.

Dretske, F. (2012b). Doubts about cogito. Grazer Philosophische Studien, 84, 1-17.

Dretske, F. (2012c). I think I think, therefore I am-I think: Skeptical doubts about selfknowledge. In J. Liu and J. Perry (Eds.), Consciousness and the self: New essays (pp. 150-164). New York: Cambridge University Press.

Evans, G. (1982). The varieties of reference. Oxford: Oxford University Press.

Fernández, J. (2013). Transparent minds: A study of self-knowledge. Oxford: Oxford University Press.

Finkelstein, D. (2003). Expression and the inner. Cambridge (MA): Harvard University Press.

Gertler, B. (2017). Self-knowledge. In E. Zalta (Ed.), Stanford Encyclopedia of Philosophy (Fall 2017 edition). URL $=$ $<$ https://plato.stanford.edu/archives/fall2017/entries/self-knowledge/>.

Hawthorne, J. (2005). The case for closure. In M. Steup and E. Sosa (Eds.), Contemporary debates in epistemology (pp. 26-43). Malden: Blackwell.

Jäger, C. (2004). Skepticism, information, and closure: Dretske's theory of knowledge. Erkenntnis, 61, 187-201.

Johnsen, B. (2001). Contextualist swords, skeptical plowshares. Philosophy and Phenomenological Research, 62, 385-406.

Kemmerling, A. (1999). How self-knowledge can't be naturalized (some remarks on a proposal by Dretske). Philosophical Studies, 95, 311-328.

Lycan, W. (1999). Dretske on the mind's awareness of itself. Philosophical Studies, 95, 125-133.

McKinsey, M. (1991). Anti-individualism and privileged access. Analysis, 51, 9-16.

Okasha, S. (1999). Epistemic justification and deductive closure. Crítica, 31, 37-51.

Parent, T. (2017). Externalism and self-knowledge. In E. Zalta (Ed.), Stanford Encyclopedia of Philosophy (Fall 2017 edition). URL = $<$ https://plato.stanford.edu/archives/fall2017/entries/self-knowledge-externalism/>.

Rieber, S. (1998). Skepticism and contrastive explanation. Nous, 32, 189-204. 
Roche, M. (2016). Knowing what one believes - In defense of a dispositional reliabilist extrospective account. American Philosophical Quarterly, 53, 365-379.

Roche, W. (2017). A condition for transitivity in high probability. European Journal for Philosophy of Science, 7, 435-444.

Roche, M., and Roche, W. (2016). Review of Declan Smithies and Daniel Stoljar's (Eds.) Introspection and consciousness (2012, Oxford University Press). Philosophical Quarterly, 66, 203-208.

Roche, M., and Roche, W. (2017). Dretske on self-knowledge and contrastive focus: How to understand Dretske's theory, and why it matters. Erkenntnis, 82, 975-992.

Sawyer, S. (2015). Contrastive self-knowledge and the McKinsey paradox. In S. Goldberg (Ed.), Externalism, self-knowledge, and skepticism: New essays (pp. 75-93). Cambridge: Cambridge University Press.

Schaffer, J. (2005). Contrastive knowledge. In T. Gendler and J. Hawthorne (Eds.), Oxford studies in epistemology: Volume 1 (pp. 235-271). Oxford: Oxford University Press.

Schwitzgebel, E. (2016). Introspection. In E. Zalta (Ed.), Stanford Encyclopedia of Philosophy (Winter 2016 edition). URL $=$ $<$ https://plato.stanford.edu/archives/win2016/entries/introspection/>.

Shackel, N. (2006). Shutting Dretske's door. Erkenntnis, 64, 393-401.

Shogenji, T. (2017). Mediated confirmation. British Journal for the Philosophy of Science, 68, 847-874.

Sinnott-Armstrong, W. (2004). Classy Pyrrhonism. In W. Sinnott-Armstrong (Ed.), Pyrrhonian skepticism (pp. 188-207). Oxford: Oxford University Press. 